\title{
Colocación de sondas nasogástricas en pacientes con COVID-19: ¿debemos preocuparnos por el riesgo de producción de aerosoles?
}

\author{
Nasogastric tube insertion in COVID-19 patients: should we worry about aerosol \\ production?
}

\author{
Enrique Cervantes-Pérez ${ }^{1,2 *}$, Lorena A. Cervantes-Pérez ${ }^{3}$, Alejandro González-Ojeda ${ }^{4}$ y \\ Carlos A. Reyes-Torres ${ }^{1}$
}

'Departamento de Nutriología Clínica, Instituto Nacional de Ciencias Médicas y Nutrición Salvador Zubirán, Ciudad de México; ${ }^{2}$ Departamento de Bienestar y Desarrollo Sustentable, Centro Universitario del Norte, Universidad de Guadalajara, Colotlán, Jalisco; ${ }^{2}$ Unidad de Trasplante de Médula Ósea, Instituto Nacional de Cancerología, Ciudad de México; ${ }^{4}$ Unidad de Investigación Biomédica 02, Hospital de Especialidades, Centro Mếdico Nacional de Occidente, Instituto Mexicano del Seguro Social (IMSS), Guadalajara, Jalisco. México

A finales de 2019, en Wuhan, China, se reportaron numerosos casos de neumonía comunitaria causada por un virus, llamado coronavirus tipo 2 asociado a síndrome respiratorio agudo grave (SARS-CoV-2). En octubre de 2020 rebasamos la preocupante cifra de 34 millones de casos en todo el mundo, con más de 1 millón de decesos. Se han hecho múltiples comparaciones con otras pandemias por coronavirus, y el impacto de la actual es cada vez más desolador.

Los coronavirus se propagan principalmente por aves y mamíferos. Las variedades genéticas más amplias infectan murciélagos, pero dos subtipos afectan al ser humano: los alfa y beta coronavirus ${ }^{1}$. Entre los coronavirus tipo beta se incluyen el SARS-CoV, el coronavirus asociado al síndrome respiratorio de Medio Oriente (MERS-CoV) y la nueva variante SARSCoV-2 productor de la COVID-19; todos estos son miembros de la familia Coronaviridae del orden Nidovirales².

Por lo anterior, existe una necesidad urgente para determinar las formas en que el virus se transmite entre los humanos $\mathrm{y}$, de esta manera, poder implementar medidas para prevenir su dispersión. Esta necesidad nace de la inminente obligación de proteger a los profesionales de la salud, quienes: en el curso de sus deberes, se expondrán a pacieñtes con COVID-19. Heinzerling, et al. ${ }^{3}$ demostraron que el $35.5 \%$ de 121 profesionales de la salud que atendieron a un solo paciente SARS-CoV-2 positivo, presentaron síntomas 14 días después de la exposición y un $2.5 \%$ dieron positivo a la prueba.

Actualmente no hay evidencia ni recomendaciones sobre el riesgo de colocación de sondas nasogástricas en pacientes con COVID-19, y la poca evidebicia disponible viene de estudios de otras enfermedades infecciosas. Una revisión sistemática encontró quellos procedimientos que aumentaban el riesgo de transmisión fueron la intubación endotraqueal, la ventilación no invasiva, la traqueostomía y la ventilación mañual antes de la intubación. De igual manera, se encontró que la colocación de sondas nasogástricas no aumeentaba significativamente el riesgo de transmisión, ăunque solo dos trabajos en pacientes con SARS-CoV-2 fueron incluidos ${ }^{4}$. Todos estos procedimientos. Son

\section{Correspondencia:}

*Enrique Cervantes-Pérez

Vasco de Quiroga, 15

Fecha de recepción: 01-10-2020

C.P. 14080 , Ciudad de México, México

E-mail: enrique.cervantes@academico.udg.mx

0009-7411/@ 2020 Academia Mexicana de Cirugi

(http://creativecommons.org/licenses/by-nc-nd/4.0/).
Fecha de aceptación: 19-10-2020

DOI: 10.24875/CIRU.20001063
Cir Cir. 2021;89(1):130-131

Contents available at Pub̆Med www.cirugiaycirujanos.com
jo la licencia CC BY-NC-ND 
considerados como generadores de aerosoles de acuerdo con las guías de salud pública de Inglaterra sobre el equipo de protección personal contra la infección por COVID-195.

Cómo tema urgente de salud pública, lo anterior invita a investigar e identificar todos los procedimientos que puedan poner en riesgo a los profesionales de la salud que a diario entran en contacto con este tipo de pacientes, ante la necesidad inminente de generar estrategias que limiten al máximo los contagios intrahospitalarios.

\section{Conflictos de intereses}

Los autores declaran no tener conflicto de intereses alguno.

\section{Financiamiento}

La presente investigación no ha recibido ninguna beca específica de agencias de los sectores público, comercial o sin ánimo de lucro.

\section{Responsabilidades éticas}

Protección de personas y animales. Los autores declaran que para esta investigación no se han rêalizado experimentos en seres humanos ni en animales.

Confidencialidad de los datos. Los autores declăran que en este artículo no aparecen datos de pacientes.

Derecho a la privacidad y consentimiento informado. Los autores declaran que en este artículo no aparecen datos de pacientes.

\section{Bibliografía}

1. Banerjee A, Kulcsar K, Misra V, Frieman M, Mossman K. Bats and coronaviruses. Viruses. 2019;11:41.

2. Memish ZA, Perlman S, Van Kerkhove MD, Zumla A. Middle East respiratory syndrome. Lancet. 2020;395:1063-77.

3. Heinzerling A, Stuckey MJ, Scheuer T, Xu K, Perkins KM, Resseger H, et al. Transmission of COVID-19 to health care personnel during exposures to a hospitalized patient - Solano County, California, February 2020. MMWR Morb Mortal Wkly Rep. 2020;69:472-6.

4. Tran K, Cimon K, Severn M, Pessoa-Silva CL, Conly J. Aerosol geñerating procedures and risk of transmission of acute respiratory infections to healthcare workers: a systematic review. PLoS One. 2012;7:e35797.

5. Public Health England. COVID-19 infection prevention and contrö guidance: aerosol generating procedures. 2020. (Updated 21 August 2020). Disponible en: https://www.gov.uk/government/publications/wuhan-novel-coronavirus-infection-prevention-and-control/covid-19-infection-prevention-and-control-guidance-aerosol-generating-procedures. 